\title{
An Interactive Tool for Automatic Predimensioning and Numerical Modeling of Arch Dams
}

\author{
D. J. Vicente, ${ }^{1}$ J. San Mauro, ${ }^{1}$ F. Salazar, ${ }^{1}$ and C. M. Baena ${ }^{2}$ \\ ${ }^{1}$ International Center for Numerical Methods in Engineering (CIMNE), Po Gral. Martínez Campos, 41, 9Izq., 28010 Madrid, Spain \\ ${ }^{2}$ Jesús Granell Ingenieros Consultores, SL, Madrid, Spain
}

Correspondence should be addressed to F. Salazar; fsalazar@cimne.upc.edu

Received 13 December 2016; Accepted 1 March 2017; Published 22 March 2017

Academic Editor: Roman Wendner

Copyright (C) 2017 D. J. Vicente et al. This is an open access article distributed under the Creative Commons Attribution License, which permits unrestricted use, distribution, and reproduction in any medium, provided the original work is properly cited.

\begin{abstract}
The construction of double-curvature arch dams is an attractive solution from an economic viewpoint due to the reduced volume of concrete necessary for their construction as compared to conventional gravity dams. Due to their complex geometry, many criteria have arisen for their design. However, the most widespread methods are based on recommendations of traditional technical documents without taking into account the possibilities of computer-aided design. In this paper, an innovative software tool to design FEM models of double-curvature arch dams is presented. Several capabilities are allowed: simplified geometry creation (interesting for academic purposes), preliminary geometrical design, high-detailed model construction, and stochastic calculation performance (introducing uncertainty associated with material properties and other parameters). This paper specially focuses on geometrical issues describing the functionalities of the tool and the fundamentals of the design procedure with regard to the following aspects: topography, reference cylinder, excavation depth, crown cantilever thickness and curvature, horizontal arch curvature, excavation and concrete mass volume, and additional elements such as joints or spillways. Examples of application on two Spanish dams are presented and the results obtained analyzed.
\end{abstract}

This work is a tribute to Jesús Granell Vicent, who put us all on the starting point of this research line

\section{Introduction}

Double-curvature arch dams are specifically intended to transfer the hydrostatic load towards the abutments in an efficient way, allowing a significant reduction of the total volume of concrete, as compared to conventional gravity dams. This feature makes them an attractive solution from an economic viewpoint. By contrast, they are only feasible in locations with certain geometrical and geotechnical properties.

The most common geometry of this type of dam is based on a reference cylinder, which is usually a conic or a circular arc of one, two, or three centers. Based on this element, the curves that determine the intrados and extrados are defined, which are in general different from each other and at each elevation. Two families of curves are therefore required to define the upstream and downstream dam faces. The resulting dam body features varying thicknesses along both the horizontal (arches) and the vertical (cantilevers) sections. The particularities of each site also contribute to the complexity of the design. They determine, for example, the depth and slope of excavation.

Frequently, one of the key aspects in the goodness of a solution is the absence of relevant tensile stress in the concrete mass. Its verification obviously requires performing a numerical calculation, at least simplified, which is also part of the design procedure.

As a result of all the abovementioned issues, the design process is cumbersome. It can be summarized in the following steps:

(1) Preliminary design

(2) Verification of the structural performance in simplified loading cases. If the result is positive, go to the 
next step. Otherwise, modify the design and repeat step (2).

(3) Detailed design including spillway, joints, and other features.

(4) Performance assessment in the loading scenarios prescribed by the corresponding regulations. If correct, the design is adopted as final. Otherwise, it is refined according to the results.

Steps (1) and (2) are typically applied on several potential locations of the dam, among which the most appropriate is selected by means of a comparative study. In this case, it is essential to have an estimate of the cost of construction, which in turn requires an approximation of the volumes of concrete and excavation.

Some publications include recommendations and procedures for the design of arch dams [1-3]. These documents are frequently used as a technical reference by engineers and practitioners in real projects. However, the described approaches do not take into account the possibilities of computer-aided design.

In other relatively frequent cases, numerical models of existing dams need to be elaborated to perform additional verifications (e.g., [4]). Only 2D drawings are typically available for such dams, from which the geometry must be obtained in three dimensions prior to the generation of the mesh and the calculation via the finite element method (FEM). This task is also cumbersome and can be automated.

This situation aroused interest in the development of tools that allow automating the design process as much as possible. As an example, the United States Bureau of Reclamation (USBR hereinafter) published a methodology to design arch dams, implemented in a spreadsheet [5]. In its current version, it can only be applied to dams with circular arches in plan view. Recently, Goulas [6] developed a procedure for the preliminary design of double-curved arch dams, compatible with the DIANA software [7].

Arch dams have also been considered for shape optimization, as reflected in the existing bibliography [8-10]. Particular emphasis has been placed on the search of optimal crown cantilever shapes and horizontal arches curvature, through different mathematical problem formulations. Nevertheless, these ideas are still far from being fully implemented in real projects.

To solve the lack of connection between traditional geometrical-design methods and new computational capabilities, an innovative software tool is presented. It covers the complete design process of double-curvature-arch-dams FEM models: preliminary geometrical design, assignation of FEM model parameters and boundary conditions, results analysis, and design improvement. This paper specially focuses on the first aspect, geometrical design, describing the most relevant steps of the process. The subsequent FEM calculations are performed by means of the Dam App, a specific application developed within the Kratos environment [11] for thermomechanical analysis of concrete dams. Since it is integrated with the pre- and postprocess software GiD [12], the tool makes use of the functionalities of the latter.
In addition, the tool allows considering the uncertainty in the knowledge of certain parameters (mostly associated with material properties) by introducing random values based on probability distributions rather than deterministic ones. This facilitates the possibility of performing stochastic calculations that can be directly integrated into general risk analysis studies $[13,14]$.

The rest of the article is organized as follows. The following section describes the functionalities of the tool and the fundamentals of the design procedure. Then, an example of application is presented and the results obtained are analyzed. The final section contains the summary and conclusions.

\section{Methodology}

This section briefly describes the functionalities of the tool, including the design criteria used. For that purpose, the most common case of predimensioning of an arch dam is described based on the topographic information of the site. The proposed methodology is summarized in Figure 1.

\subsection{Design Process for Alternatives Studies}

2.1.1. Topography Upload. The design process starts with the selection of the dam location within a predefined area, whose topographical information is typically available. It can be uploaded either as a computer-aided graphical design file (.dxf extension) or as a 3-column structured text file with the $X / Y / Z$ coordinates information of each point. The tool makes use of the GiD's functionality to automatically generate the ground surface and the topographic contour lines, with a user-defined equidistance (in $\mathrm{m}$ ) in the vertical direction ( $z$ axis).

2.1.2. Reference Cylinder. Once the ground surface is created, the dam axis can be defined by means of a reference cylinder with vertical axis. Its cross section can be circular, as suggested by the USBR with one, two, or three arches $[2,5]$. Two- and three-centered lines are more common in the design of real dams, as they adapt better to different shapes of valleys and allow better load distribution due to the resulting variable curvature $[1,3]$.

More complex curves as ellipses, parabolas, logarithmic spirals, and catenary curves are also used [5]. Goulas [6] proposed a three-curved line compounded by three parabolas, one for the center part and the other two for the left and right side banks, to achieve variable thickness and curvature. Zingoni et al. [15] analyzed elliptic-paraboloid dams with parabolic reference cylinder to assess the effect of buckling stresses as compared to single-curvature parabolic dams.

The presented tool allows selecting between elliptical and parabolic cylinders. The latter was chosen for illustrating the design process, which is described in the following sections. Parabolas are defined by means of the focus and vertex, which can be graphically set by the user (Figure 1(b)). The only relevant difference for the case of elliptical cylinder is that the length of the minor axis also needs to be defined.

It should be noted that most circular arcs can be approximated with ellipses with enough accuracy, if necessary. 


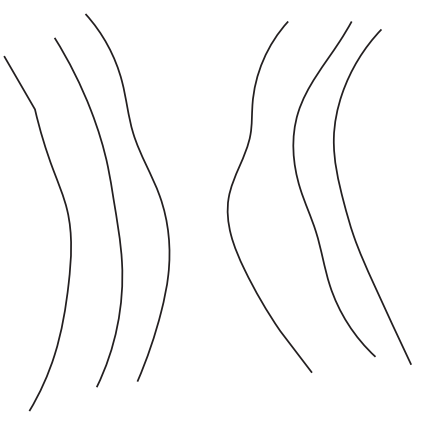

(a) Topography

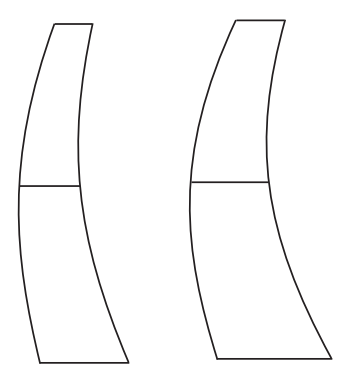

(d.1) Thickness

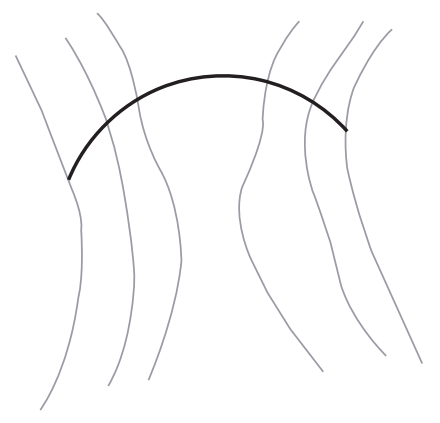

(b) Reference cylinder

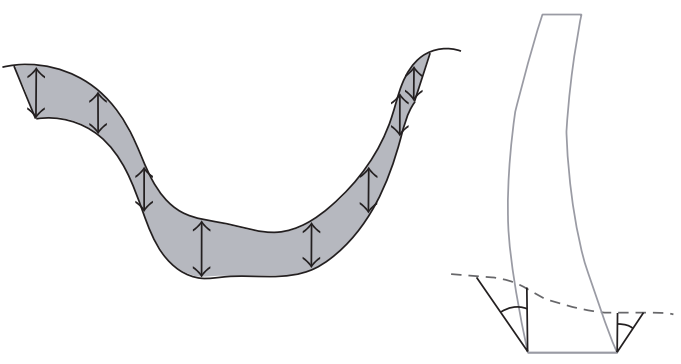

(c) Excavation depth

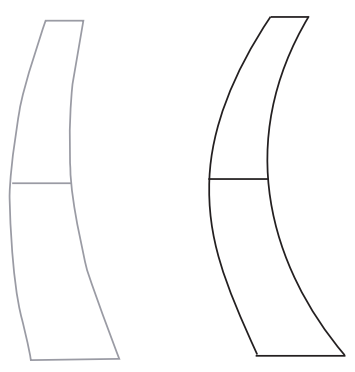

(d.2) Curvature

(d) Central cantilever

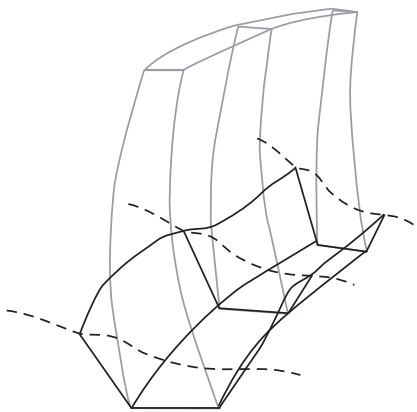

(f) Excavation and dam body

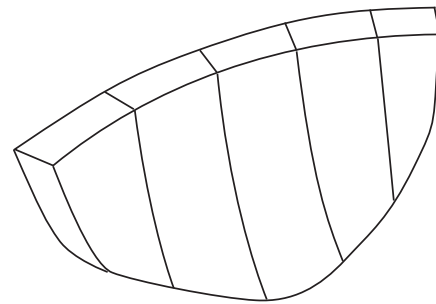

(g) Joints

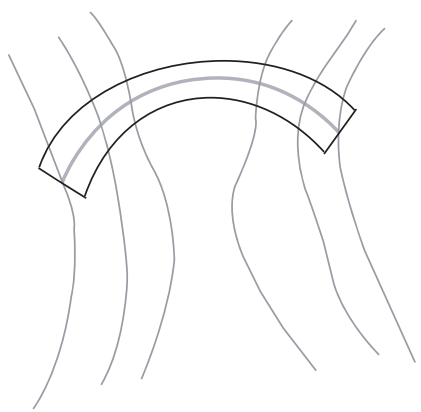

(e) Arches

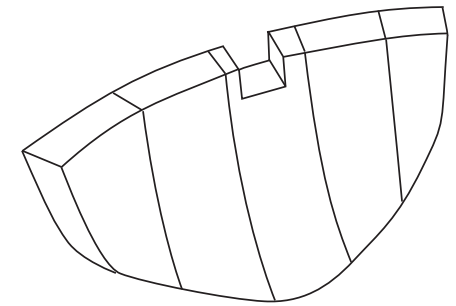

(h) Spillway

FIGURE 1: Flowchart of the design process.

2.1.3. Foundation. Dam foundation is typically situated below the ground surface to reach a sound rock layer. Weak areas must be removed to provide a firm foundation, without sharp breaks and irregularities, capable of withstanding the applied loads, including hydrostatic and self-weight [1]. To meet that requirement, the tool allows the user to define different excavation depth at ten elevations in each margin. The intersection is computed between the reference cylinder and correspondent copies of the ground surface, located at a vertical distance equal to the excavation depth (Figure 1(c)). A default value of $7.5 \mathrm{~m}$ was set as recommended by the USBR [5]. It can be used for preliminary design, in case there is no available information on the foundation properties.

The complete definition of the excavation requires the selection of the appropriate slope (Figure 1(c)). It should be determined taking into account the rock properties (both mechanical and hydraulic) and the dam typology, which also conditions the excavation technique [16].
Not infrequently, different rock formations are encountered along the dam foundation [17], which results in different values of the excavation slope. To account for this issue, the application allows defining different excavation slopes for each margin and for the riverbed area.

2.1.4. Crown Cantilever: Thickness. The load distribution in arch dams must be adequate between arches and crown cantilevers, for which dam thickness is essential. It typically varies vertically along the dam body.

We implemented the method proposed by the USBR [2], where the central cantilever thickness at the crest $\left(\mathrm{Th}_{\text {crest }}\right)$, at the foundation $\left(\mathrm{Th}_{\text {found }}\right)$, and at $45 \%$ of the height $\left(\mathrm{Th}_{0.45}\right)$ is computed according to the following expressions:

$$
\begin{aligned}
\mathrm{Th}_{\text {crest }} & =0.01 \cdot\left(H+1.2 \cdot L_{\text {crest }}\right), \\
\mathrm{Th}_{\text {found }} & =\sqrt[3]{0.0012 \cdot H \cdot L_{\text {crest }} \cdot L_{\text {found }} \cdot\left(\frac{H}{400}\right)^{H / 400}},
\end{aligned}
$$




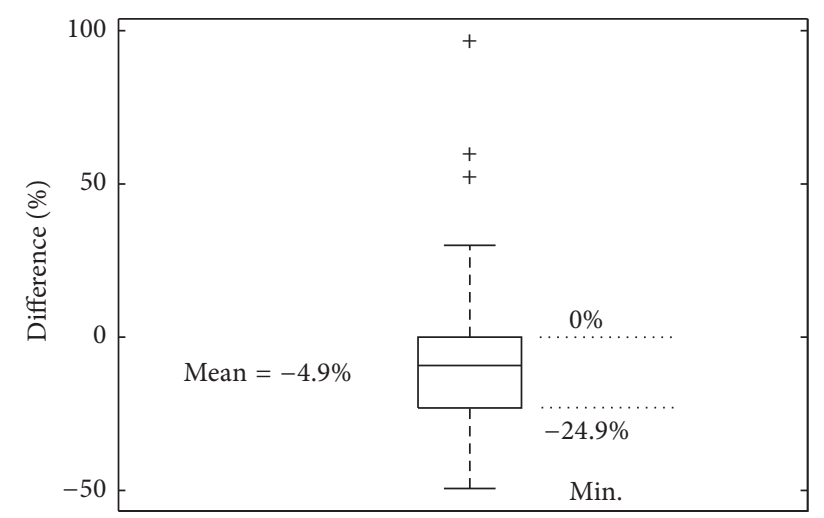

FIGURE 2: Comparison between USBR-suggested thickness and that used in real dams.

$$
\mathrm{Th}_{0.45}=0.95 \cdot \mathrm{Th}_{\text {found }} \text {, }
$$

where $H$ is the dam height and $L_{\text {crest }}$ and $L_{\text {found }}$ are the chordal lengths at crest and foundation, respectively. With the purpose of increasing flexibility in the design process, the three values can be modified by introducing a factor. Since it can be higher or lower than 1, the resulting thickness can be greater or lower than the default one (Figure 1(d)).

These functionalities allow various possibilities: (a) to reproduce the geometry of an existing dam with variable thickness, (b) to make a preliminary design of a dam based on the USBR criterion, or (c) to adapt such design according to the particularities of the case or the results of numerical models.

The actual thickness at the top of the crown cantilever of 30 international arch dams was compared to those obtained with (1) (Figure 2). It can be seen that the default value is around 5\% higher than the average for this collection.

2.1.5. Crown Cantilever: Curvature. The curvature of the central cantilever is set in three steps (Figure 3). Initially, $\mathrm{Th}_{\text {crest }}, \mathrm{Th}_{\text {found }}$, and $\mathrm{Th}_{0.45}$ are placed according to the USBR method [2].

In the second step, to ensure complete flexibility in the design process, the position of $\mathrm{Th}_{\text {found }}$ and $\mathrm{Th}_{0.45}$ can be modified in order to revise the initial curvature. The relocation is handled by means of the parameters $\alpha_{1}$ and $\alpha_{2}$, which define the percentage of $\mathrm{Th}_{\text {found }}$ and $\mathrm{Th}_{0.45}$ located upstream and downstream the dam axis, respectively.

Finally, upstream and downstream ends of the three segments are joined by circular arcs that define the correspondent faces of the central cantilever, as shown in Figure 3. Other criteria can be adopted such as adjusting polynomials of second order as functions of the height $[7,9,10]$. These approaches are related to theoretical optimization models and involve the use of additional parameters.

2.1.6. Shape and Location of Arches. The lines of centers define the horizontal shape of the arches for each elevation, starting at the crown cantilever and curving horizontally downstream towards the abutments. As conic curves are used instead of circular arcs, these lines are defined by the focal points of the curves (Figure 4).

Some authors published methodologies to define the lines of centers. USBR [5] proposed several options depending on whether uniform or varying thickness is selected: one, two, or more lines, respectively. For all cases, a straight line and a compound of straight plus a circular arch are proposed, resulting in different rules of variation. Li et al. [9] calculated the optimal position of the center at each elevation, obtaining an irregular line of centers compounded by several linear segments. Goulas [6] suggested a polynomial of an order proportional to the number of arches used to define the dam faces. In other studies, the horizontal arches are generated without prior examination of the line of centers. Delgado and Márquez [18] suggested an algorithm to generate constituent curves of a certain number of horizontal arches by polynomial interpolation methods.

Any of these procedures can be approximated with the tool. As the reference cylinders selected are quadratic curves (either parabola or ellipse), the lines of centers are determined by the position of the focuses of the parabola or the ellipse, respectively. Two different lines of centers must be introduced to define the intrados and extrados dam faces, in order to achieve varying thickness. Users can define the position of each focus just entering its distance $\left(d_{i}\right.$ and $d_{e}$ for intrados and extrados, resp.) to the correspondent dam face and for each level $z$ (see Figure 4).

2.1.7. Model Fitting and Volume Calculation. Once the abovementioned steps have been completed, all the necessary information for defining the dam body is available. Hence, it is generated, as well as the excavation. The volumes of concrete mass and excavation can be directly obtained from the resulting $3 \mathrm{D}$ model. Figure 5 shows an example of the result.

Before performing any numerical calculation, it is useful to visualize the shape of the dam and in particular that of the vertical and horizontal sections, which define the arches and the cantilevers. These sections are automatically generated and displayed on screen. If necessary, the user can modify some of the parameters entered and generate a new geometry (Figure 6).

Once the geometry obtained is considered adequate, further details can be added to be accounted for in the calculation. In particular, joints between blocks and the spillway can be defined (see Figure 7). In the first case, the width of each block must be entered, and in the second, the position of each bay of the spillway. This results in the geometric definition of the dam, ready for the FEM analysis.

2.2. Additional Functionalities. Although the tool was mostly designed for automatizing the design process, it can also be useful for other types of analysis, which are briefly described in this section.

2.2.1. Simplified Geometries. Simplified models can be generated based on a limited number of geometrical parameters: dam height, crest and foundation chord lengths, plan view 


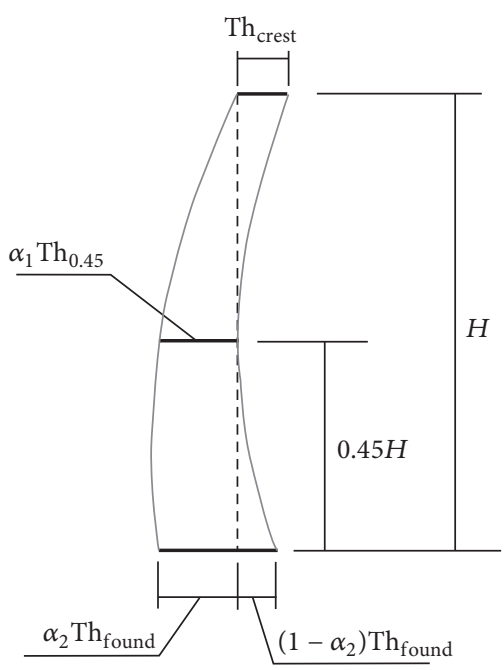

(a) Default values: $\alpha_{1}=1 ; \alpha_{2}=0.67$

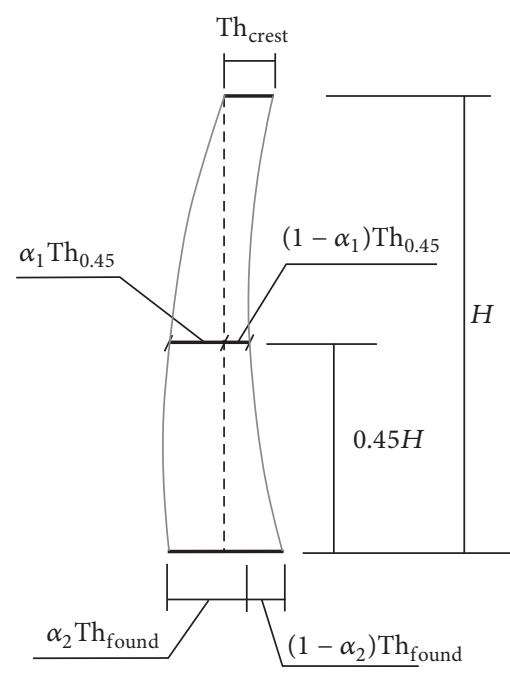

(b) Custom values

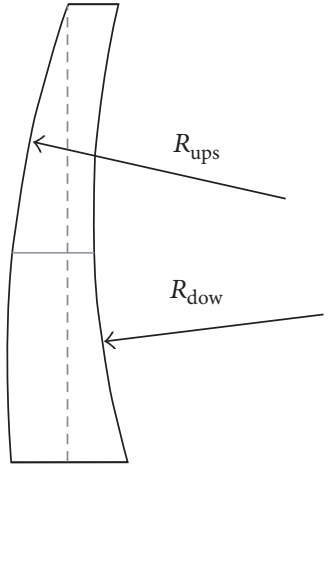

(c) Arc fitting

Figure 3: Steps to define crown cantilever thickness and curvature. (a) Default location [2]. (b) User-defined location of $\mathrm{Th}_{0.45}$ and $\mathrm{Th}_{\text {found }}$. (c) The faces of the central cantilever are defined by circular arcs.
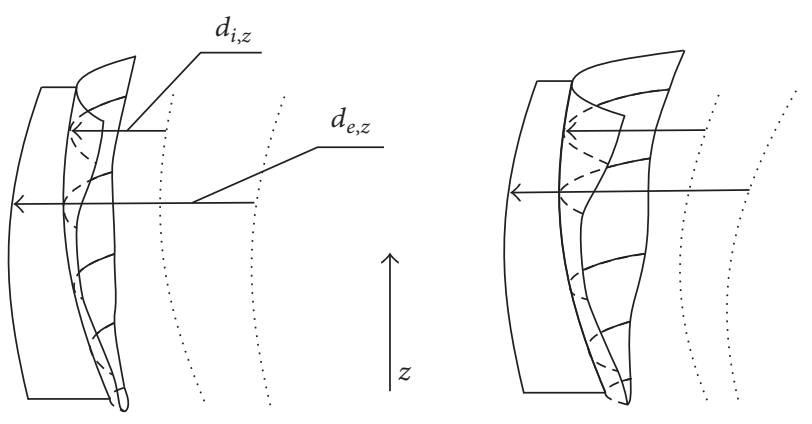

FIGURE 4: Definition of lines of centers (focuses in the case of parabolas) for both intrados and extrados faces. The shape variation in the intrados is depicted for illustration purposes. The same effect can be achieved for the upstream face. It should be noted that the crown cantilever is not modified in this step.

angles, and thickness widening at abutments. This functionality can be applied when detailed topographic information is not available or required for the objectives of the study (e.g., academic or scientific purposes). Initially, crest and foundation thickness and crown cantilever curvature are calculated according to USBR method [2]. The user can later modify the resulting values by entering specific parameters to change thicknesses and cross section curvature.

Material properties are divided into two groups: concrete mass and foundation. External loads are also limited to a certain number of relevant cases. Self-weight load is always considered while hydrostatic and thermal loads are optional. Hydrostatic load is defined by adding water level in percentage units of the total height of the dam. For thermal loads, a sinusoidal function is created to represent ambient temperature through the introduction of three parameters: mean temperature, amplitude, and phase of the function.
Water temperature can be defined to be either uniform for the whole water mass or time- and depth-dependent, according to an empirical distributed law proposed by Bofang [19].

These simplified geometries are currently being employed for a sensitivity analysis on the effect of geometrical and material parameters on dam behavior. One of the main objectives of this study is to analyze the performance of arch dams located in valleys of different shapes: narrow- $\mathrm{V}$, wide- $\mathrm{V}$, narrow-U, or wide-U [1]. Figure 8 shows some examples of models generated with this level of detail.

Such studies require a large number of cases to be computed; hence, the parametric generation of FEM models and their automatic calculation was imperative. Similar tools were developed for rock-fill dams [20].

2.2.2. Consideration of Uncertainty on Model Parameters. In recent years, there has been a tendency towards performing probabilistic rather than deterministic calculations [21, 22]. This approach allows considering the uncertainty associated with the value of certain parameters, such as the strength of the concrete or foundation. Hence, the results can be integrated in an overall risk analysis associated with a given mode of failure [13].

In this framework, the developed tool allows following any of the two approaches (deterministic and probabilistic), since each parameter can be defined either as a fixed value or as a random variable following a given probability distribution law: uniform, normal, and lognormal, among others. This functionality allows the integration of the calculations in the framework of risk analysis [14].

2.2.3. Detailed Models. The same procedure can be used in the case of existing dams with no numerical models available. This is a relatively frequent situation (e.g., [4]), which requires drawing each cross section, locating them in 

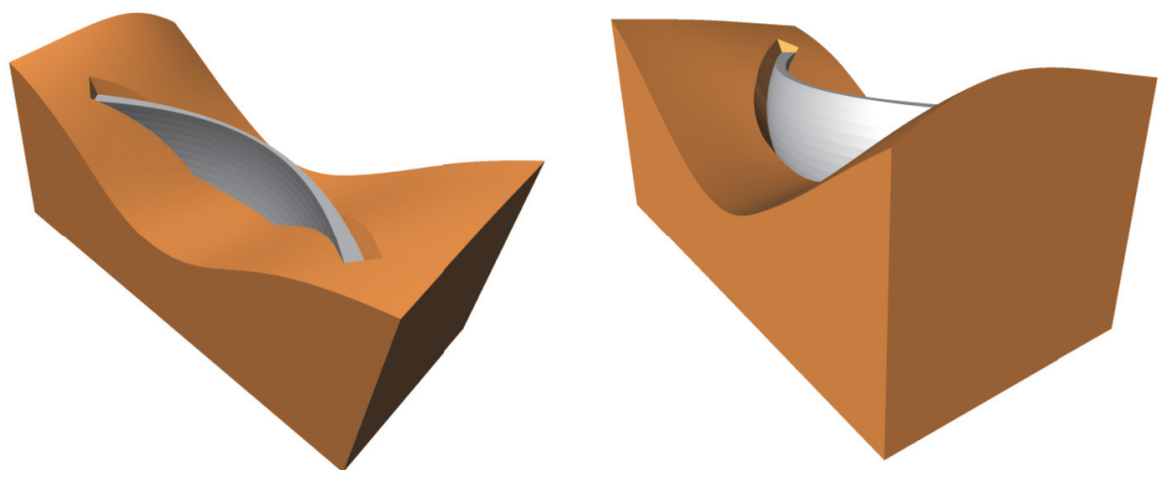

FIGURE 5: Example views of dam body and excavation geometry.

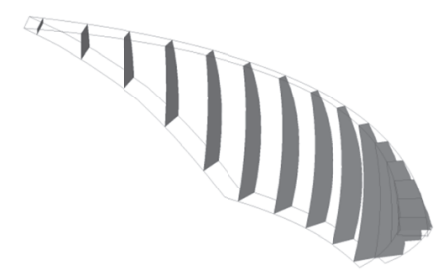

(a)

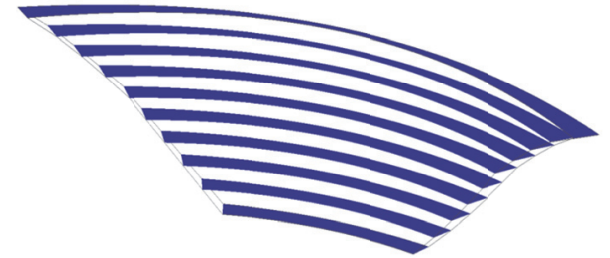

(b)

FIGURE 6: Display of cantilever sections (a) and horizontal arches (b).

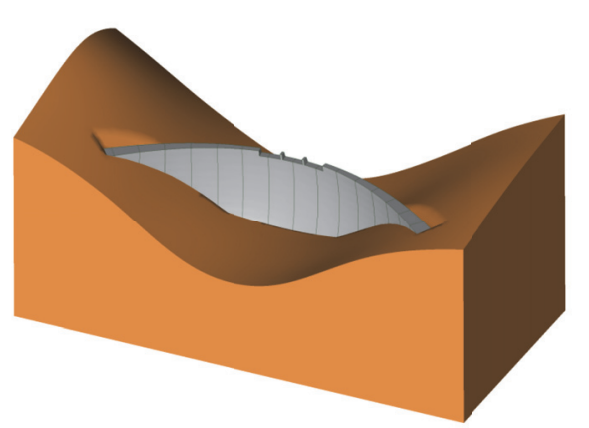

FIGURE 7: Complete geometry including joints and spillway.

their correspondent position in $3 \mathrm{D}$, joining them to create surfaces and volumes, generating the ground geometry, and then creating the mesh.

With the new tool, this process can be automatized and simplified. The procedure is essentially the same as described in Sections 2.1.1-2.1.7, though much simpler, because the actual information of the dam (which is usually available) can be introduced: reference cylinder, thickness, crown cantilever curvature, arches location, excavation depth, foundation geometry, and so forth. As a result, there is no need to iterate back and forth to refine the design.

\section{Example of Application}

La Baells Dam is a doubled-curvature arch dam located on the Llobregat River in the Catalonian region of Spain. It was
TABLE 1: Material properties considered in the FEM model.

\begin{tabular}{lccc}
\hline Property & Units & Dam & Foundation \\
\hline Young Modulus & $\mathrm{N} \cdot \mathrm{m}^{-2}$ & $4.76 \cdot 10^{10}$ & $3.10 \cdot 10^{10}$ \\
Poisson ratio & - & 0.25 & 0.25 \\
Density & $\mathrm{kg} \cdot \mathrm{m}^{-3}$ & 2400 & 3000 \\
Thermal conductivity & $\mathrm{W} \cdot \mathrm{K}^{-2} \cdot \mathrm{m}^{-1}$ & 2.4 & 2.2 \\
Thermal expansion coeff. & $\mathrm{K}^{-1}$ & $10^{-5}$ & $10^{-5}$ \\
Specific heat & $\mathrm{J} \cdot \mathrm{kg}^{-1} \cdot \mathrm{K}^{-1}$ & 982 & 950 \\
\hline
\end{tabular}

taken as a principal benchmark in this study to show different capabilities of the developed tool.

Geometric information was facilitated by the Catalan Water Agency and used in previous studies related to the analysis of its behavior [23-25]. The same applies to the properties of the materials, which are included in Table 1.

Several functionalities of the tool are presented for illustration purposes.

(1) The numerical model and the mesh were generated based on the cross section, plan, and front view drawings and on the geometric definition of the arches in the intrados and extrados. As a result, a detailed 3D geometry was obtained that was then used to perform a thermomechanical calculation. The results were compared to the available data of pendulum displacement in terms of the maximum range of variation.

(2) The necessary information was extracted for the generation of a simplified geometry according to the procedure described in Section 2.2.1, mainly the dam height, the width 
TABLE 2: Density functions for the parameters considered as random variables.

\begin{tabular}{lcccr}
\hline Parameter & Units & Mean & Coefficient Variation (\%) & Range (95\%) \\
\hline Elastic modulus (dam) & $\mathrm{N} \cdot \mathrm{m}^{-2}$ & $4.76 \cdot 10^{10}$ & 11.0 & {$\left[3.71 \cdot 10^{10}-5.81 \cdot 10^{10}\right]$} \\
Elastic modulus (foundation) & $\mathrm{N} \cdot \mathrm{m}^{-2}$ & $3.10 \cdot 10^{10}$ & 11.0 & {$\left[4.9 \cdot 10^{9}-3.43 \cdot 10^{10}\right]$} \\
Thermal exp. coeff. (dam) & $\mathrm{K}^{-1}$ & $9.45 \cdot 10^{-6}$ & 16.7 & {$\left[6.3 \cdot 10^{-6}-1.26 \cdot 10^{-5}\right]$} \\
\hline
\end{tabular}

TABLE 3: Comparison between calculated parameters and real ones.

\begin{tabular}{lcccccc}
\hline & La Baells & & & \multicolumn{2}{c}{ Baserca } \\
Real & Calculated & Difference (\%) & Deal & Calculated & Corence $(\%)$ \\
\hline Dam volume $\left(\mathrm{m}^{3}\right)$ & 324,816 & 382,000 & 15 & 197,829 & 230,000 & 14 \\
\hline
\end{tabular}

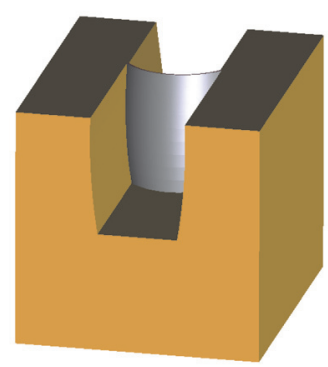

(a)

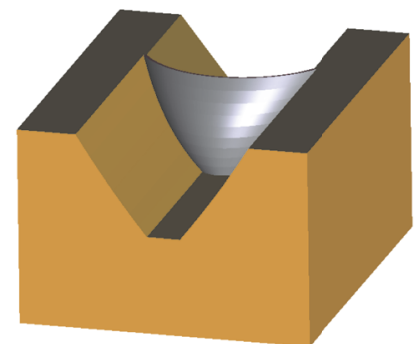

(b)

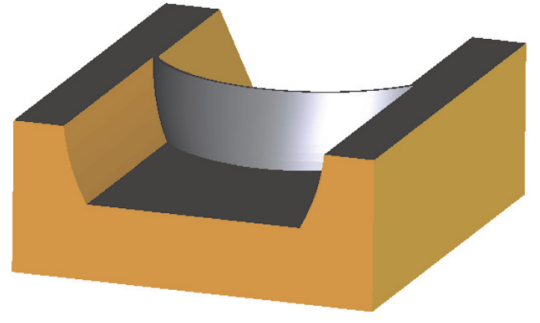

(c)

Figure 8: Examples of three dam models with different site shapes: (a) narrow-U, (b) narrow-V, and (c) wide-U valleys.

of the valley at foundation and crest, and the thicknesses and curvature (both in plan and cross section views).

Both models (simplified and detailed) were calculated in two loading scenarios: with and without hydrostatic load. In both cases, a simulation period of 4 years was considered, during which the ambient temperature was varied according to the air temperature data also available (sinusoidal variation of average $13^{\circ} \mathrm{C}$ and range between 2 and $24^{\circ} \mathrm{C}$ ). Water temperature was estimated according to Bofang's law.

(3) A probabilistic analysis was also performed taking into account the uncertainty of three of the most relevant material properties (modulus of elasticity of concrete and foundation and thermal expansion coefficient of concrete). A total of 1,000 calculations were performed, with all three values randomly selected from Gaussian distributions, whose parameters are included in Table 2.

Mean values of modulus of elasticity for both concrete and foundation are those included in Table 1. The coefficient of variation of concrete was extracted from Vilardell et al.s study [26] who suggested different values for dam concrete according to its age. Since the present analysis focused on an existing dam, a value associated with 180 days was considered. The same value is assumed for the coefficient of variation of the foundation. In the case of the thermal expansion coefficient, mean and standard deviation were fitted to obtain the range proposed by FERC [27], with a 95\% probability of occurrence. Figure 9 shows the probability distribution functions defined and the random values generated.
Finally, the 3D FEM model of Baserca Dam was generated from the plan and cross section views. It is another doublecurvature arch dam, located in Huesca (Spain), with $87 \mathrm{~m}$ maximum height above foundation and $300 \mathrm{~m}$ chord length at crest [4].

\section{Results and Discussion}

4.1. 3D Model Generation. Upstream and downstream views of the 3D detailed models generated for La Baells and Baserca Dams are included in Figures 10 and 11, respectively. The dam body, excavation, and spillways can be observed. We made use of GiD's rendering capabilities to yield realistic images, with shadows and appropriate colors for the dam body, ground, and water.

The dam body volume was computed from the FEM model and compared to that reported by SPANCOLD [28] (Table 3). For both dams, the model featured lower volume, because the reference value considered all the concrete employed in the construction, including, for instance, the spillway chute for La Baells Dam, as well as other auxiliary works. By contrast, the model volume strictly corresponds to the dam body.

The simplified model for La Baells Dam is depicted in Figure 12. The ground geometry is also simple, though its influence is minor in the results.

4.2. Thermomechanical Analysis. Figure 13 shows the maximum and minimum displacement at the crown cantilever for 


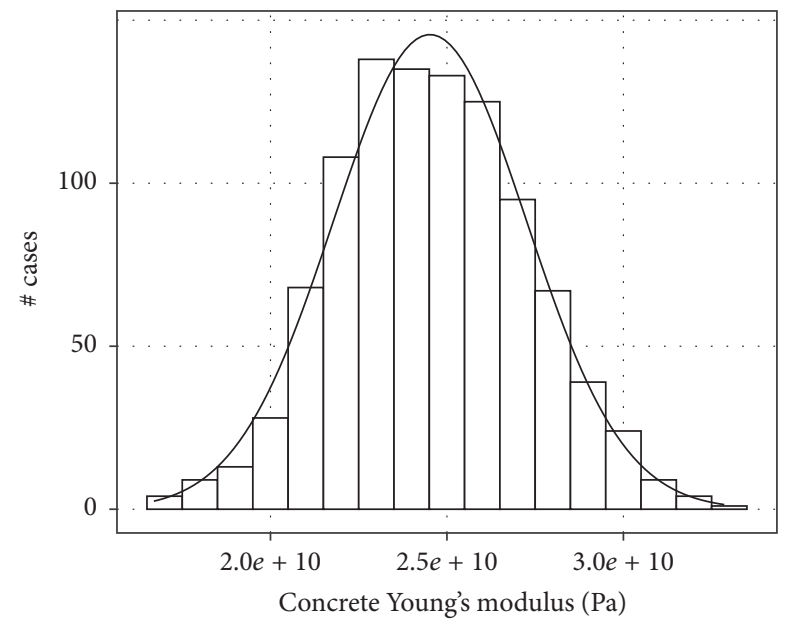

(a)

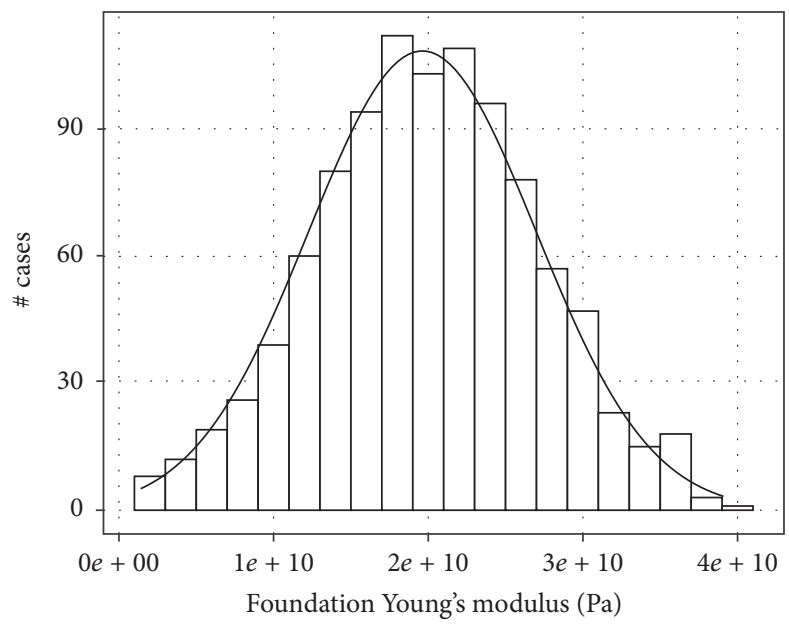

(b)

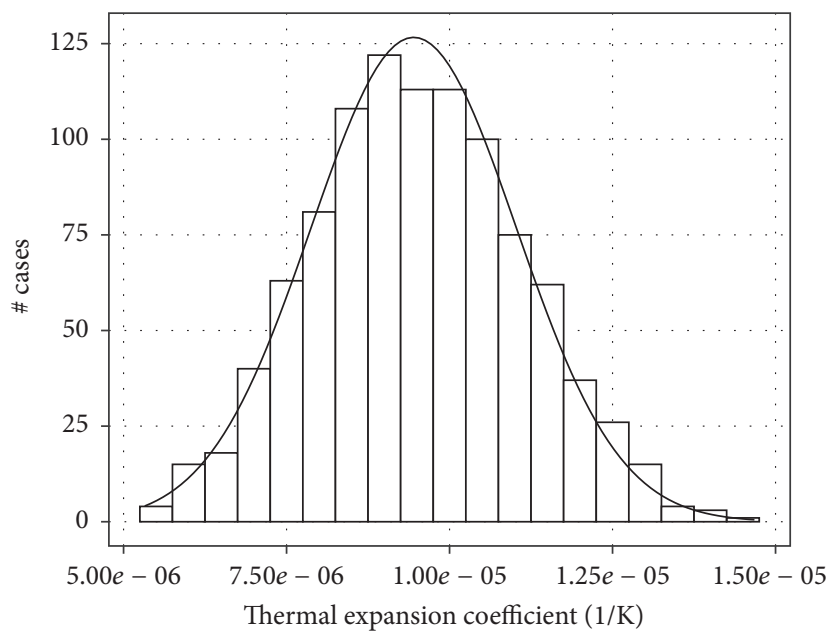

(c)

FIGURE 9: Histograms of automatically obtained values and probability distribution functions (Gaussian normal).

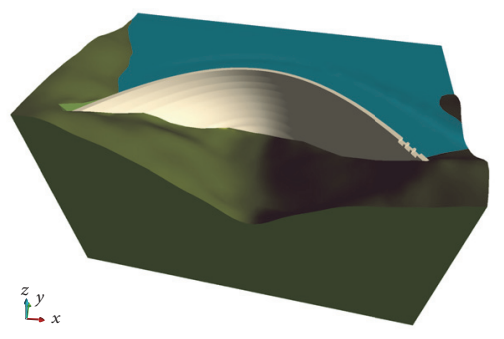

(a)

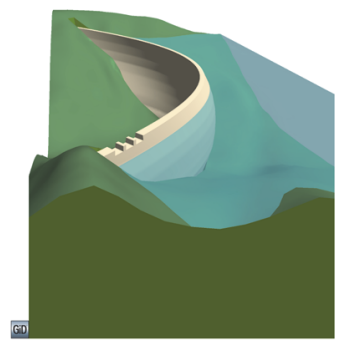

(b)

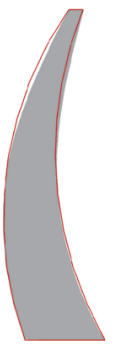

Actual crown cantilever - Model

(c)

FIgURE 10: La Baells Dam model. View from downstream (a), view from the left abutment (b), and crown cantilever section (c). 


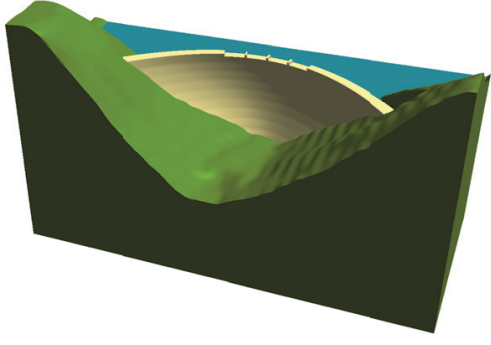

(a)

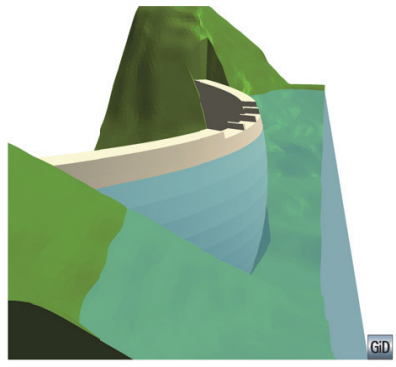

(b)

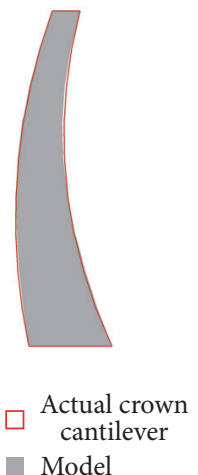

(c)

Figure 11: Baserca Dam model. View from downstream (a), view from the left abutment (b), and crown cantilever section (c).

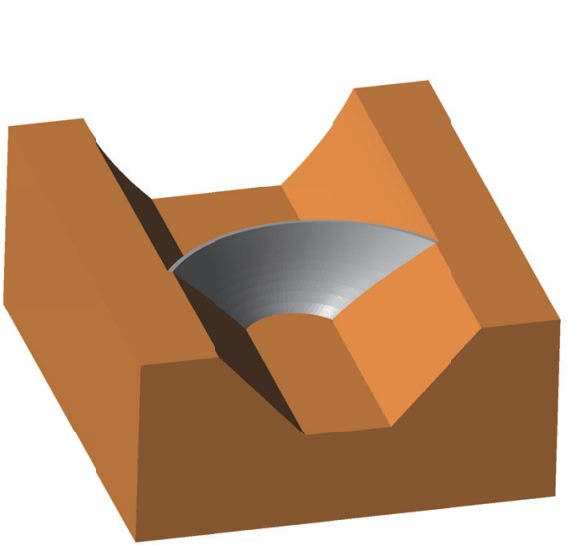

(a)
Detailed model Simplified model

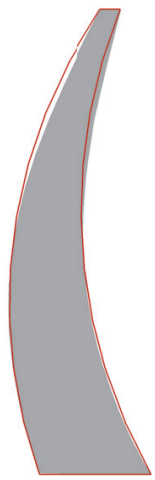

(b)

FIGURE 12: (a) View from downstream of the simplified model for La Baells Dam. (b) Comparison between the detailed and the simplified models.
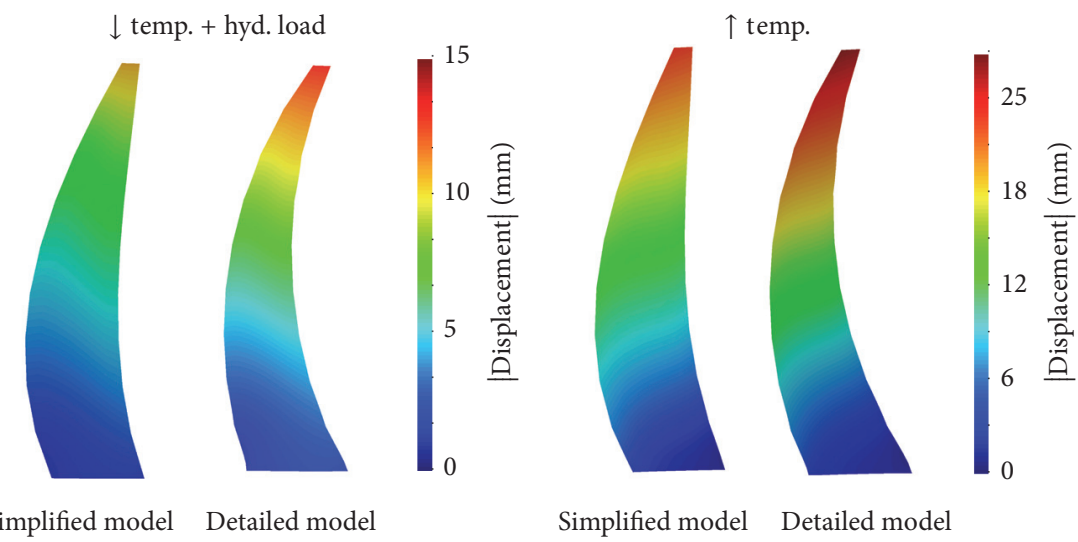

FIGURE 13: Displacement in the crown cantilever of La Baells Dam as computed with the simplified and detailed models.

the simplified and detailed models for La Baells Dam. They correspond to the expected load combinations:

(1) The maximum displacement towards downstream is registered for temperature decrease combined with the maximum hydrostatic load (full reservoir).
(2) The maximum displacement towards upstream was obtained with no hydrostatic load (empty reservoir) in combination with temperature increase.

The displacement fields are similar for the correspondent load combinations in both models, though the simplified one is 


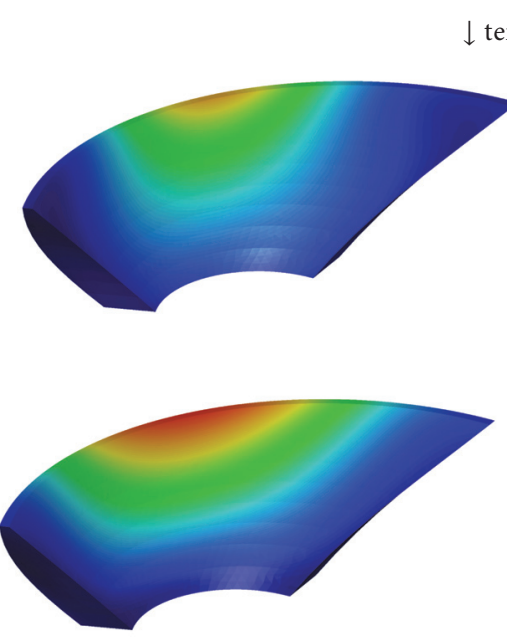

Simplified model temp. + hyd. load

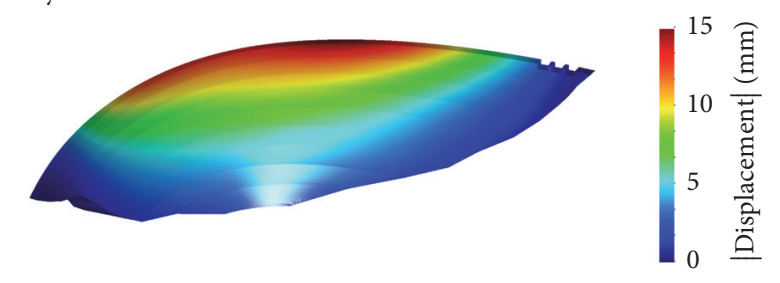

$\uparrow$ temp.

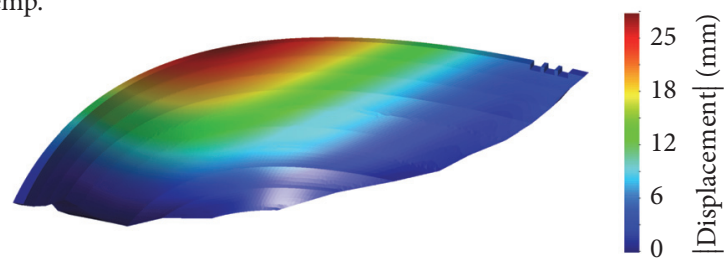

Detailed model

FIgURE 14: Displacement field for La Baells Dam.

more rigid (lower displacement) due to its higher average thickness (Figure 13).

The same result can be observed in the overall view from downstream (Figure 14). The abovementioned higher thickness makes the displacement more concentrated in the vicinity of the crown cantilever. The different level of detail is also reflected in the asymmetry of the displacement field of the detailed model.

The range of variation at the location of one of the pendulums was extracted and compared to monitoring data. In particular, we focused on the radial displacement at 610 m.a.s.l. in one of the central cantilevers (see the location of the monitoring devices in [24]). The results were $30.6 \mathrm{~mm}$ for the detailed model and $18.6 \mathrm{~mm}$ for the simplified one.

The recorded monitoring data showed a range of variation of $24 \mathrm{~mm}$ in the blocks located near the central cantilever [23]. It should be noted that while the minimum hydrostatic load for the available measurement period was $62 \%$, the model was computed for $0 \%$. It is thus logical that the range of displacement is lower for the real dam. Taking that difference into account, the result of the detailed model is a useful estimate to the observed behavior.

The difference between the two numerical models is mostly due to the higher thickness of the simplified one.

4.3. Probabilistic Analysis. The results of the probabilistic analysis can be presented as empirical density functions, where the effect of the considered uncertainty is reflected. For demonstration purposes, we focused on (a) the displacement at the top of the crown cantilever, (b) the compression stress at the base of the central cantilever, and (c) the tensile stress at the upstream toe.

The results of this type of analysis could be employed to define warning thresholds for key performance indicators in the first filling and subsequent months. Since not enough monitoring data are available for that period, they must be

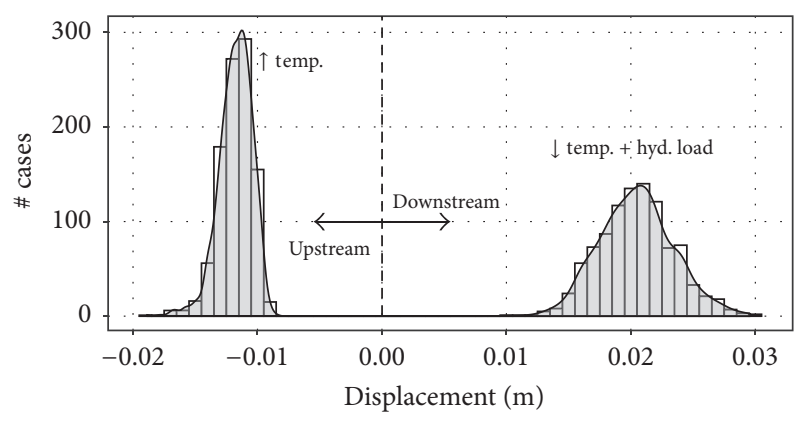

Figure 15: Displacement at the top of the crown cantilever.

based on numerical models, and stochastic results provide more useful information for that purpose.

For instance, a deterministic analysis would yield a single result for the maximum displacement towards downstream, close to the mean of the empirical distribution $(0.02 \mathrm{~m}$; Figure 15). Any observed higher value could be considered as anomalous. However, if it actually fell in the central area of the empirical distribution of the results, it should be attributed to the uncertainty in the parameter values, hence normal.

Results correspondent to stresses (Figures 16 and 17) can be useful to estimate the probability of exceedance of the compression and tensile strength of the concrete, or to prescribe them during the design stage.

\section{Summary and Conclusions}

An innovative tool for computer-aided design of arch dams was presented. It allows automatizing the design process, taking into account the key parameters: shape of arches and cantilevers, excavation depth and slope, and additional details such as spillway and joints. The reference cylinder can be 


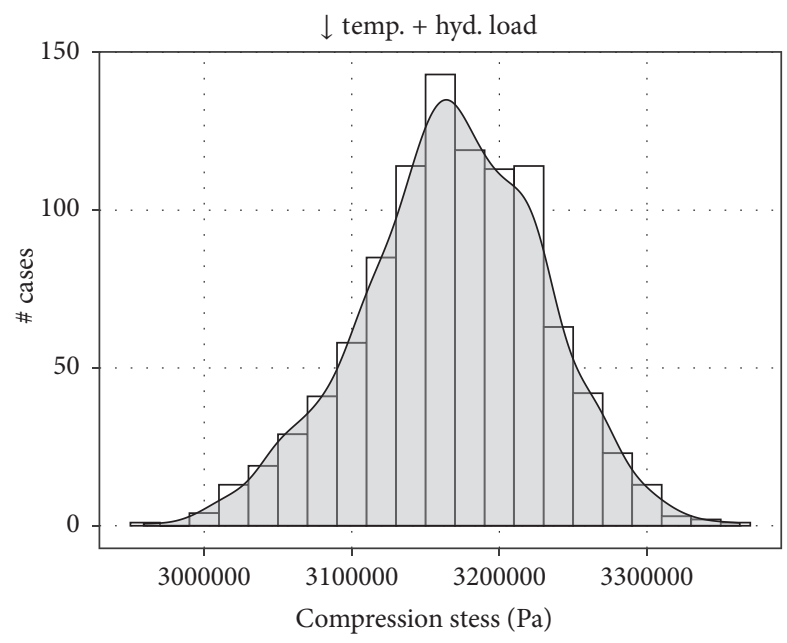

(a)

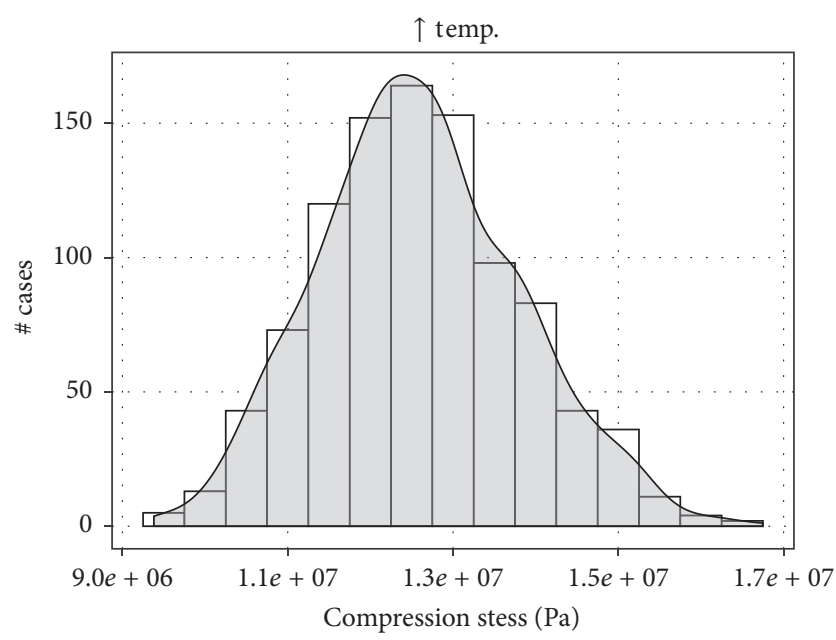

(b)

FIgURE 16: Compression stress. (a) At the downstream toe (full reservoir, temperature decrease). (b) At the upstream toe (empty reservoir, temperature increase).

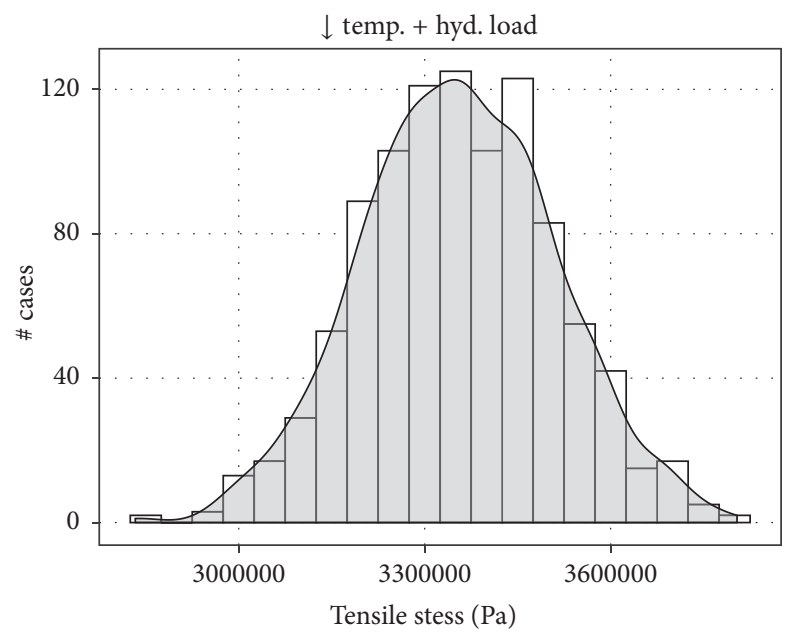

FIgURE 17: Tensile stress at the upstream toe.

elliptical or parabolic, which allows for adapting to any valley shape, including those asymmetrical.

The USBR methodology is followed by default [5], though the resulting geometry can be modified by the user with a high degree of flexibility.

The design procedure is integrated into a FEM code developed in the Kratos environment [11], so that the mesh and boundary conditions can be directly defined to calculate typical load scenarios.

The tool is also integrated with the pre- and postprocess software GiD [12], which allows taking advantage of its functionalities both for pre- and for postprocess. This widens the possibilities for extracting detailed results. Nonetheless, the tool allows automatically computing the volume of concrete and excavation for each of the designs considered in an alternatives study.
Although the tool was mainly designed for automatizing the design process of new dams, it can also be useful for other types of analysis. Simplified geometries can be suitable for academic or scientific purposes, or when certain information is not available (e.g., topographic information).

Probabilistic analysis can be carried out considering random values for certain parameters, instead of deterministic ones, through the introduction of probability distributions laws. This allows taking into account the uncertainty associated with certain material properties and conducting stochastic calculations to be used in risk analysis.

The results show that the tool can be useful for researchers and practitioners in various fields related to the design and performance assessment of arch dams: preliminary design, alternatives study, safety assessment, and probabilistic and sensitivity analysis, among others.

\section{Conflicts of Interest}

The authors declare that there are no conflicts of interest regarding the publication of this paper.

\section{Acknowledgments}

The authors kindly acknowledge Professor Toledo, from UPM, for his useful advice. Thanks are also due to Ignasi de Pouplana and Lorenzo Gracia, the main developers of the Dam App in Kratos, who contributed to the seamless integration of this tool with the FEM code. The authors also gratefully acknowledge Carlos Barbero, Dam Safety Manager at the Catalan Water Agency, and María Chacón, from ENDESA Generación, for providing information for La Baells and Baserca Dams, respectively. They also acknowledge the financial support to CIMNE via the CERCA Programme/Generalitat de Catalunya. The research was also supported by the Spanish Ministry of Economy and 
Competitiveness (Ministerio de Economía y Competitividad, MINECO) through the projects AIDA (BIA2013-49018-C2-1$\mathrm{R})$ and ACOMBO (RTC-2015-3794-5). This work is a tribute to Jesús Granell Vicent, who put us all on the starting point of this research line.

\section{References}

[1] USACE-US Army Corps of Engineers, Ed., Arch Dam Design, Capítulo 8, USACE, Washington, DC, USA, 1994.

[2] USBR-US Bureau of Reclamation, Design Criteria for Arch and Gravity Dams-Engineering Monograph No 19, US Government Printing Office, Denver, Colo, USA, 1977.

[3] E. Vallarino, Tratado Básico de Presas-Tomo I (4 Edición), Canales y Puertos, Colegio de Ingenieros de Caminos, Barcelona, Spain, 1998.

[4] B. Suárez Arroyo, J. Miquel Canet, J. M. González Lopez et al., "The behavior of Baserca and Llauset dams in the new energetic scenarios," in Proceedings of the 9th ICOLD European Club Symposium: Sharing Experience for Safe and Sustainable Water Storage, p. 144, Venice, Italy, April 2013.

[5] USBR-US Bureau of Reclamation, "Design of double-curvature arch dams planning, appraisal, feasability level," Technical Memorandum EM36-86-68110, 2013.

[6] E. Goulas, Design of double-curvature arch dams in terms of geometric and stress constraints by using script-based finite element modelling [M.S. thesis], Delft University of Technology, Delft, Netherlands, 2016.

[7] DIANA 9 (Displacement Analyzer), "Users Manual. Release 9," The Delft, The Netherlands: TNO Diana Inc.

[8] S. Gholizadeh and S. M. Seyedpoor, "Optimum design of arch dams for frequency limitations," International Journal of Optimization in Civil Engineering, vol. 1, pp. 1-14, 2011.

[9] S. Li, L. Ding, L. Zhao, and W. Zhou, "Optimization design of arch dam shape with modified complex method," Advances in Engineering Software, vol. 40, no. 9, pp. 804-808, 2009.

[10] S. M. Seyedpoor, J. Salajegheh, E. Salajegheh, and S. Gholizadeh, "Optimal design of arch dams subjected to earthquake loading by a combination of simultaneous perturbation stochastic approximation and particle swarm algorithms," Applied Soft Computing Journal, vol. 11, no. 1, pp. 39-48, 2011.

[11] P. Dadvand, R. Rossi, and E. Oñate, "An object-oriented environment for developing finite element codes for multidisciplinary applications," Archives of Computational Methods in Engineering, vol. 17, no. 3, pp. 253-297, 2010.

[12] R. Ribó, M. A. R. Pasenau, E. Escolano, J. S. P. Ronda, and L. F. González, GiD Reference Manual, CIMNE, Barcelona, Spain, 1998.

[13] L. Altarejos García, I. Escuder Bueno, A. J. Serrano Lombillo, and M. Gómez De Membrillera Ortuño, "Methodology for estimating the probability of failure by sliding in concrete gravity dams in the context of risk analysis," Structural Safety, vol. 36-37, pp. 1-13, 2012.

[14] G. Wang and Z. Ma, "Application of probabilistic method to stability analysis of gravity dam foundation over multiple sliding planes," Mathematical Problems in Engineering, vol. 2016, Article ID 4264627, 12 pages, 2016.

[15] A. Zingoni, K. Mudenda, V. French, and B. Mokhothu, "Buckling strength of thin-shell concrete arch dams," Thin-Walled Structures, vol. 64, pp. 94-102, 2013.
[16] Y. Zhang, W. Lu, M. Chen, P. Yan, and Y. Hu, "Dam foundation excavation techniques in China: a review," Journal of Rock Mechanics and Geotechnical Engineering, vol. 5, no. 6, pp. 460467, 2013.

[17] J. Liu, X.-T. Feng, X.-L. Ding, J. Zhang, and D.-M. Yue, "Stability assessment of the Three-Gorges Dam foundation, China, using physical and numerical modeling-Part I: physical model tests," International Journal of Rock Mechanics and Mining Sciences, vol. 40, no. 5, pp. 609-631, 2003.

[18] A. H. Delgado and L. Márquez, "Modelling of an arch dam by polynomial interpolation," Mathematics and Computers in Simulation, vol. 79, no. 12, pp. 3434-3443, 2009.

[19] Z. Bofang, "Prediction of water temperature in deep reservoirs," Dam Engineering, vol. 8, no. 1, pp. 13-25, 1997.

[20] P. Yi, J. Liu, and C. Xu, "Reliability analysis of high rockfill dam stability," Mathematical Problems in Engineering, vol. 2015, Article ID 512648, 8 pages, 2015.

[21] Z. Jiang and J. He, "Method of fusion diagnosis for dam service status based on joint distribution function of multiple points," Mathematical Problems in Engineering, vol. 2016, Article ID 9049260, 10 pages, 2016.

[22] G. Yang and M. Yang, "Multistage Warning Indicators of Concrete Dam under Influences of Random Factors," Mathematical Problems in Engineering, vol. 2016, Article ID 6581204, 12 pages, 2016.

[23] F. Salazar, M. A. Toledo, E. Oñate, and R. Morán, “An empirical comparison of machine learning techniques for dam behaviour modelling," Structural Safety, vol. 56, pp. 9-17, 2015.

[24] F. Salazar, M. Á. Toledo, E. Oñate, and B. Suárez, "Interpretation of dam deformation and leakage with boosted regression trees," Engineering Structures, vol. 119, pp. 230-251, 2016.

[25] D. Santillán, E. Salete, D. J. Vicente, and M. Á. Toledo, “Treatment of solar radiation by spatial and temporal discretization for modeling the thermal response of arch dams," Journal of Engineering Mechanics, vol. 140, no. 11, Article ID 05014001, 2014.

[26] J. Vilardell, A. Aguado, L. Agullo, and R. Gettu, "Estimation of the modulus of elasticity for dam concrete," Cement and Concrete Research, vol. 28, no. 1, pp. 93-101, 1998.

[27] FERC-Federal Energy Regulatory Commission Division, Ed., Engineering Guidelines for the Evaluation of Hydropower Projects, Chapter 11-Arch Dams, RIDM-Regulations, Guidelines and Manuals, Comission of Dam Safety and Inspections, Washington, DC, USA, 1999.

[28] SPANCOLD—Comité Español de Grandes Presas, Selección de Presas Españolas 1973-1993, Centro de Publicaciones Ministerio de Obras Públicas, Transportes y Medio Ambiente, 1994. 


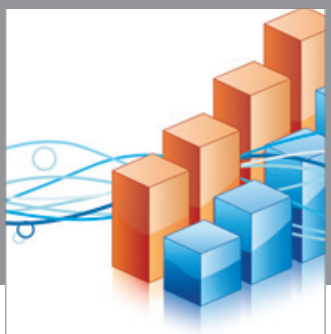

Advances in

Operations Research

vatem alat4

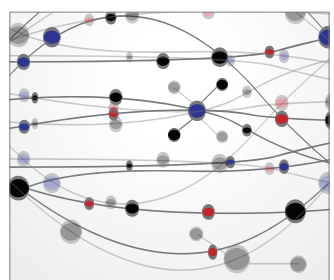

\section{The Scientific} World Journal
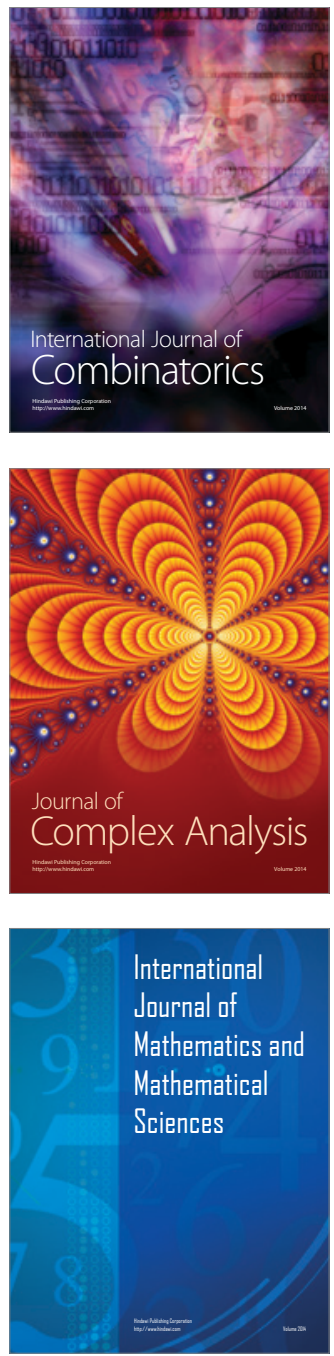
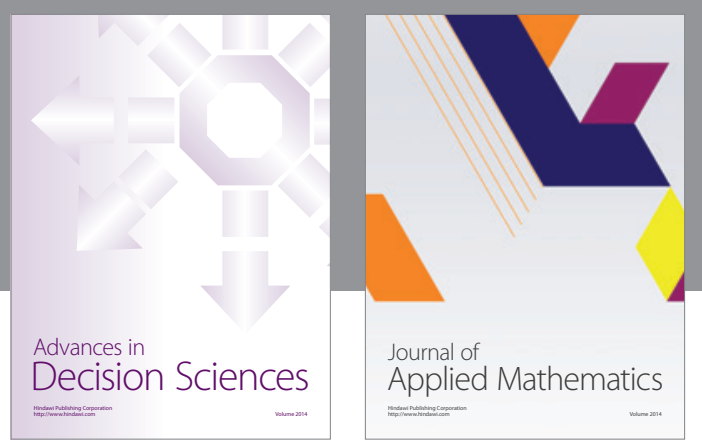

Algebra

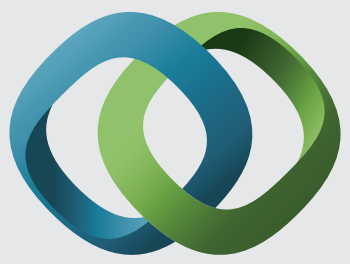

\section{Hindawi}

Submit your manuscripts at

https://www.hindawi.com
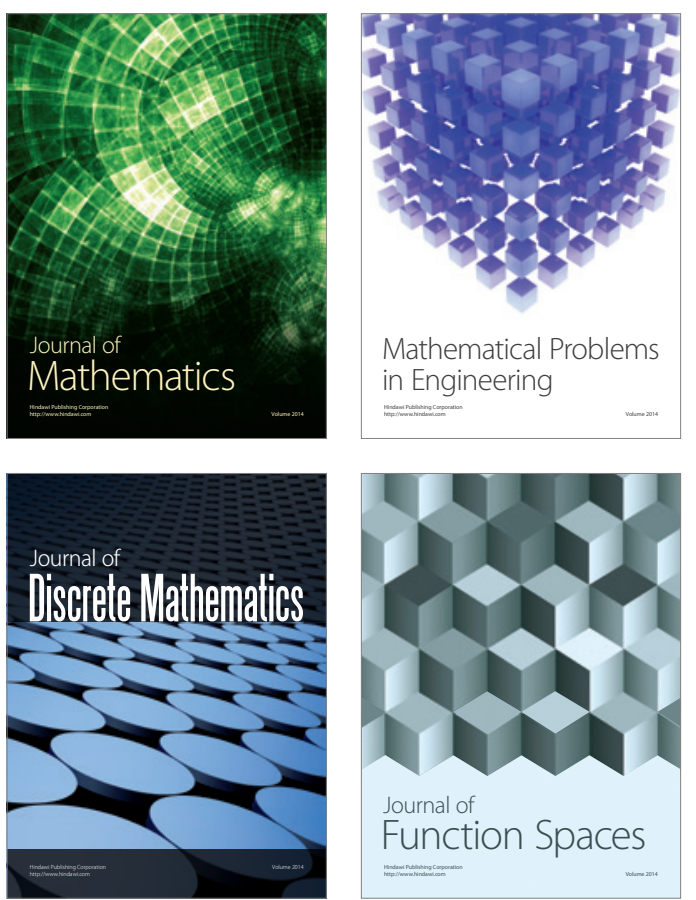

Mathematical Problems in Engineering
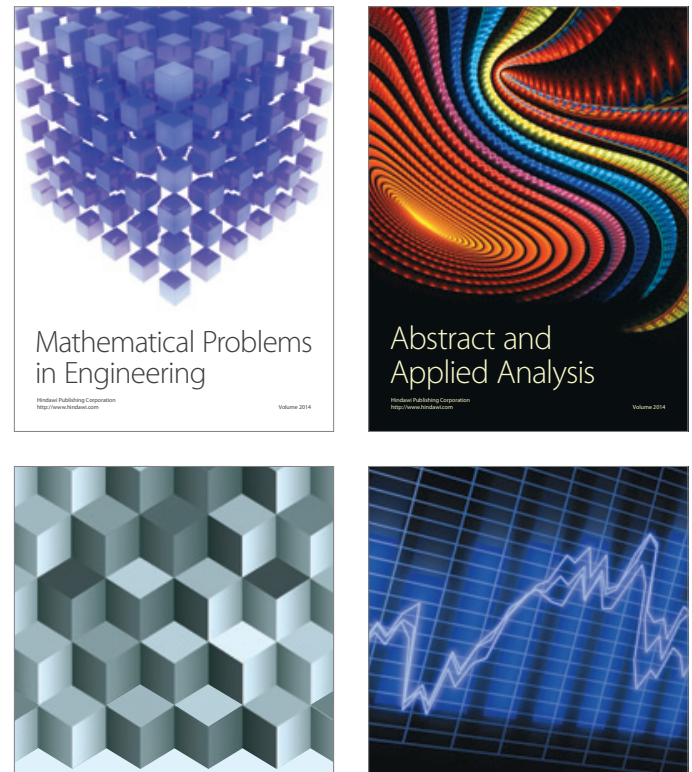

Journal of

Function Spaces

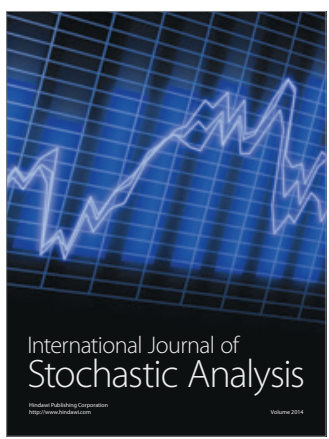

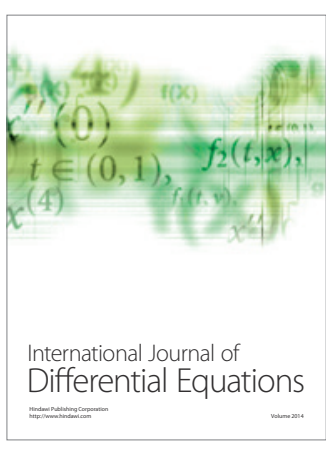
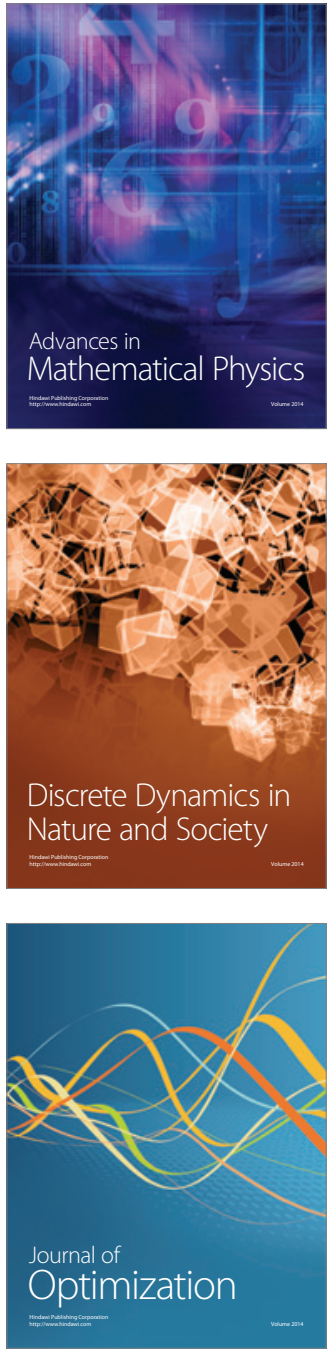